\title{
Novos olhares para a juventude: descobrindo caminhos ${ }^{1}$
}

\author{
Marta Carvalho de Almeida, Carla Regina Silva Soares, Ana Terra dos Santos Barbosa, \\ Danielle Peralta Kazanji, Mariana Silva Lima, Pérola Prado
}

Departamento de Fisioterapia, Fonoaudiologia e Terapia Ocupacional, Universidade de São Paulo - USP,

São Paulo, SP, Brasil.

\begin{abstract}
Resumo: Trata-se de apresentar e discutir referências conceituais e práticas do projeto O território e seus protagonistas: novos olhares para a infância e juventude, que tem se desenvolvido como atividade de extensão universitária em Terapia Ocupacional Social pelo núcleo da USP do Projeto Metuia. As atividades têm por foco a juventude que reside na região do Butantã, no município de São Paulo, as suas famílias e, em especial, os profissionais que atuam com esse segmento. Seu objetivo é influir na produção coletiva de novas representações sociais sobre a juventude, confrontando preconceitos. Oferece condições para a reelaboração crítica das representações sociais que desqualificam o jovem e suas ações, promovendo o encontro e o diálogo entre jovens protagonistas de iniciativas culturais ou de experiências exitosas na esfera da defesa dos direitos, e profissionais e/ou familiares ligados ao desafio de oferecer proteção e oportunidades para o desenvolvimento integral dos jovens. Observações que se desdobram da concretização do projeto sugerem que, embora se encontrem na região iniciativas importantes, originadas em coletivos juvenis, de modo geral os jovens não têm encontrado estímulo para desenvolver seu papel protagônico na esfera das produções culturais. A despeito das dificuldades enfrentadas para viabilizar o encontro dialogado entre jovens, profissionais e comunidade, o desenvolvimento do projeto tem permitido que se observem atitudes solidárias e a valorização da pluralidade cultural entre os jovens.
\end{abstract}

Palavras-chave: Juventude, Protagonismo, Cultura, Terapia Ocupacional.

\section{New perspectives on youth: discovering pathways}

\begin{abstract}
This article aims to present and discuss some conceptual and practical references of the project enitled "The territory and its protagonists: new perspectives for childhood and youth", that has been developed as an academic extension activity of Social Occupational Therapy by members of the Metuia Project at University of São Paulo. The project activities focus on the young people living in Butantã neighborhood, in the city of São Paulo, their families and, specially, the professionals that work with this group. Its goal is to influence the collective production of new social representations on youth, confronting prejudices. It offers conditions for a critical review of social representations that disqualify youth and their actions, promoting meetings that bring together young protagonists of cultural actions or successful experiences related to youth rights and professional and/or family members that must provide protection and opportunities for the full development of young people. Observations suggest that while important initiatives originating from youth groups are present in that region, generally young people have not found encouragement to develop a leadership role in cultural productions. Despite the difficulties to bring together young people, professionals and the community, the project allow us to observe solidarity among young people and their relish for the cultural diversity.
\end{abstract}

Keywords: Youth, Protagonist, Culture, Occupational Therapy. Autor para correspondência: Marta Carvalho de Almeida, Universidade de São Paulo, Rua Cipotânea, 51, Cidade Universitária Armando de
Salles Oliveira, Butantã, CEP 05360-000, São Paulo, SP, Brasil, e-mail: mcarmei@usp.br

Recebido em Maio 24, 2015; $1^{\text {a }}$ Revisão em Jul. 30, 2015; Aceito em Ago. 31, 2015. 


\section{Introdução}

\subsection{Os motivos}

As reflexões que aqui serão apresentadas têm integrado as experiências práticas de terapia ocupacional que se realizam por meio dos projetos de extensão universitária desenvolvidos pelo Núcleo USP (Universidade de Sáo Paulo) do Metuia - projeto interinstitucional que abrange atividades de ensino, pesquisas e açóes com pessoas, grupos e comunidades em situação de vulnerabilidade ou risco social no âmbito da Terapia Ocupacional Social. Inserem-se no plano de discussóes sobre a cultura - tomada enquanto campo de estruturas de significados construídos pelos homens (GEERTZ, 2008) - e as práticas sociais voltadas à juventude.

A atuação profissional com a juventude da zona oeste da cidade de Sáo Paulo teve início no ano de 2012, quando, em parceria com unidade socioassistencial do SUAS - Sistema Único de Assistência Social -, membros do Núcleo USP do Projeto Metuia e estudantes de terapia ocupacional atuaram na coordenação de encontros semanais com jovens participantes do Serviço Socioeducativo para Adolescentes e Jovens de 15 a 17 anos (ProJovem Adolescente). Temas como sexualidade, trabalho, política, drogas, escola, saúde e cultura guiaram as discussóes e atividades propostas ao grupo, levando em conta os interesses manifestados e o diálogo com o traçado metodológico proposto para o serviço (BRASIL, 2009). O grupo era constituído por jovens de ambos os sexos que, em sua maior parte, frequentavam escolas públicas e realizavam cursos profissionalizantes em unidades da rede socioassistencial.

Posteriormente, entre 2013 e 2014, as açôes se desenvolveram com jovens em cumprimento de medida socioeducativa em meio aberto, na modalidade "Prestação de Serviços à Comunidade", acumulada ou não com a modalidade "Liberdade Assistida". Tais modalidades compóem as medidas socioeducativas previstas no Estatuto da Criança e do Adolescente (ECA), com base na consideração de que o jovem menor de 18 anos é penalmente inimputável, mas pode ser responsabilizado socialmente por infraçóes cometidas. Assim, o jovem pode ser submetido a alguma das seis medidas socioeducativas que, dispostas em grau de severidade, serão aplicadas considerando-se alguns aspectos, dentre os quais a capacidade dele em cumpri-las, bem como as circunstâncias em que sucedeu a infração e sua gravidade (BRASIL, 1990). As medidas em meio aberto são definidas por autoridade judiciária e devem ser conduzidas pelo SUAS, por meio do Serviço de Proteção Social a Adolescentes em Cumprimento de Medida Socioeducativa de Liberdade Assistida (LA) e de Prestação de Serviços à Comunidade (PSC). $\mathrm{Na}$ proposta desenvolvida pelo Projeto Metuia, foram realizadas atividades em grupo com os jovens acompanhados, em ambientes internos e externos à unidade assistencial prestadora do serviço, e também o acompanhamento individual de alguns jovens.

Dentre outros aspectos, essas experiências foram marcadas pela oportunidade de se perceber a força negativa de concepçóes que desqualificam, desvalorizam e/ou menosprezam as expressóes e produçóes individuais ou coletivas do universo juvenil, e que, reunidas a outros elementos, compóem uma cultura ${ }^{2}$ que naturaliza e legitima a violação de direitos desse segmento social.

Observou-se, sobretudo, que, de forma clara ou sutil, estereótipos, preconceitos e uma profunda descrença na potência e na capacidade de ação daqueles jovens predominavam como referências que orientavam as relaçóes que, com eles, os adultos estabeleciam. Com poucas exceçóes, essas referências atravessavam todo o território sociorrelacional envolvido nas atividades realizadas, incluindo desde as famílias até os equipamentos assistenciais, limitando - ou até mesmo impedindo - o acesso desses jovens às oportunidades de obterem proteção, se desenvolverem integralmente e exercitarem a participação social, conforme se prevê na doutrina da proteção integral adotada pelo ECA.

Embora a presença de tais representações não constituísse um fato imprevisto, tendo em vista que um imaginário social negativo em relação aos jovens tem sido amplamente afirmado na literatura, surpreendia que predicados tâo depreciativos estivessem enraizados de forma tão naturalizada, tanto no senso comum quanto na rede profissional que a estes jovens deve oferecer apoio e proteção. Não havia - considerando-se nossa experiência imediata - distinção significativa entre as representaçôes manifestadas nessas duas esferas.

Coube, então, instituir um processo pelo qual, conforme propóem Barros et al. (2007), busca-se pela apreensão das dinâmicas culturais em jogo, bem como pelos códigos e símbolos em interação ou conflito. Tal busca, como se sabe, tem sido componente importante das açóes e estratégias que se desenvolvem no campo da Terapia Ocupacional Social. 


\subsection{Compreendendo o que se via}

Uma leitura importante sobre a realidade encontrada se fez com base em Abramo (2007), que mostrou como a tematização sobre juventude no senso comum - apoiada em representaçôes construídas pelo pensamento acadêmico e difundidas pelos meios de comunicação e por outros atores sociais - se liga às dificuldades de se ultrapassar a visão do jovem como sinônimo de problema.

Juventude, conforme a autora, tem sido uma categoria propícia para simbolizar os dilemas da contemporaneidade, quer seja no plano do pensamento acadêmico, quer seja no âmbito da opinião pública. Apresentando-se como um retrato projetivo da sociedade, a juventude condensa as angústias e as esperanças do nosso tempo em relação às tendências sociais notadas no presente e suas possíveis repercussôes no futuro. Sua concepção mais difundida socialmente se assenta na corrente funcionalista da sociologia, que a considera como um momento de transição da infância para a maturidade. Assim, pensada como um processo de desenvolvimento que visa ao ajuste aos papéis adultos, a juventude é tomada como um momento crucial para a manutenção da coesão social, pois as "disfunçôes" nesse processo, afinal, podem representar rupturas importantes. Nesse sentido, são as "falhas" nesse desenvolvimento e ajuste que se tornam objetos da preocupação social e fazem da juventude um "problema".

Abramo (2007) lembra que a percepção dos jovens como um problema social já foi discutida por vários autores e que, desde a segunda metade do século passado, a juventude vem sendo tematizada de forma a se tornar depositária de certa dose de medo. A autora refaz o percurso do imaginário social partindo dos anos de 1950, quando o problema da juventude era representado por sua predisposiçáo para a transgressão e delinquência. Retoma, então, os anos de 1960 e 1970, nos quais se identificava, nos jovens, tanto a ameaça à ordem social nos planos político, cultural e moral quanto a possibilidade de transformação social profunda. Essa noção, tendo inicialmente gerado medo, foi mais tarde reelaborada de forma a identificar aquela geração com uma imagem positiva: idealista, generosa e comprometida com as mudanças sociais. Assim, foi em contraste com essa imagem que a juventude dos anos de 1980 foi percebida socialmente, comenta Abramo (2007). Individualismo, apatia, consumismo e indiferença com os assuntos públicos foram associados a ela. A juventude continuou, desse modo, sendo depositária do medo. Mas, naquela ocasião, do medo do "fim da História”, uma vez que era tomada como uma geraçấo que negava seu papel como fonte de mudança.

Será, então, somente nos anos de 1990 que, conforme a autora, as figuras juvenis mais evidenciadas no Brasil serão os jovens pobres, os meninos de rua, infratores, participantes das gangues e das galeras, e, principalmente, os jovens considerados em "situaçáo de risco", retomando o foco nos problemas de comportamento que se havia visto nos anos de 1950. Como uma das imagens mais dramáticas e ameaçadoras, surge a imagem dos jovens envolvidos no tráfico, matando e morrendo muito cedo.

Ao concluir, discutindo as imagens difundidas na década de 1990 sobre a juventude, a autora ressalta que seu interesse é mostrar como se confinaram os jovens a uma ideia de desregramento social. E que, sobre estes, se podem até produzir atitudes de compaixão e salvação, se considerada a lógica que os constrói como vítimas. Porém, não se instituiu, de fato, a capacidade de enxergá-los como sujeitos capazes de qualquer tipo de ação propositiva, mesmo quando é essa a intenção. A dificuldade, ressalta, é de incorporá-los enquanto sujeitos capazes de formular questôes significativas, de propor açóes relevantes e de sustentar uma relaçáo dialógica com outros atores, participando de processos de definição, invenção e negociação de direitos.

Esse cenário revela um problema contemporâneo complexo. Da perspectiva do imaginário social, o lugar ocupado pelos jovens tem sido contraditório, uma vez que não se fixa na esfera da liberdade e do novo, nem na da desordem ou do descontrole. Ao mesmo tempo, ao se considerar o mundo real no qual se desenvolvem as relaçóes humanas, sua inserção não tem permitido o exercício da autonomia e da emancipação. Esteves e Abramovay (2007) afirmam que, embora os jovens tenham alcançado um lugar de destaque no mercado - tornando-se, até mesmo, um parâmetro para o consumo estético -, o acirramento das desigualdades produzidas pela sociedade capitalista tem contribuído decisivamente para que, ao contrário do que pode parecer, estes se encontrem mais dependentes do seu núcleo familiar e com menores chances de decidirem sobre seu próprio destino. Em outras palavras, ainda que o jovem tenha sido alçado à condição de um consumidor poderoso, e que ser jovem tenha se tornado um slogan, sua condição é paradoxal.

Dessa perspectiva, a publicação La juventud em Iberoamérica - tendencias y urgências, de 2004, destacou dez paradoxos ou tensões constitutivas da atual condição juvenil, as quais foram apresentadas de modo sumarizado em recente publicação da Secretaria Nacional da Juventude (BRASIL, 2014). 
Dentre esses, ao menos dois se associam diretamente à esfera das representaçôes sociais sobre a juventude.

O primeiro paradoxo destaca que o novo padrão de consumo cultural da juventude, especialmente em relação à indústria audiovisual, tem fornecido ícones e referências que permitem à grande parte desse grupo gerar identidades coletivas e participar de universos simbólicos. Mesmo sendo essas referências pouco consolidadas e mutantes, estas fazem da juventude um ator social com grande capacidade criativa no âmbito da cultura. Porém, muitas vezes as identidades geradas são fragmentárias e tornam-se fechadas em si mesmas, na medida em que encontram dificuldades para se harmonizar com o mundo adulto e com figuras de autoridade. O emblema desse paradoxo é a coexistência de uma forte conexão interna, ou seja, entre jovens de um mesmo grupo, e experiências de exclusão em relação ao conjunto da sociedade.

O segundo paradoxo diz respeito ao lugar ambíguo que a juventude ocupa na esfera do discurso público. Os jovens são, simultaneamente, definidos como receptores de políticas sociais e como protagonistas de mudanças societárias. Por conseguinte, já não são os próprios jovens que projetam sua identidade e suas aspiraçóes para o conjunto da sociedade, mas, pelo contrário, são projetados pelas políticas sociais. E, frequentemente, como "vulneráveis" ou "carentes". Ocorre que, em oposição a essa visão, os jovens realmente operam sobre o seu mundo e geram novas sensibilidades e novas identidades, sobretudo por meio do consumo cultural e da comunicação. Assim, se por um lado, a idade os coloca na condição de receptores de instâncias de formação e disciplinamento, por outro lado, se difunde o mito de uma juventude que protagoniza novas formas de relaçáo social. A juventude fica, nessa posição, tensionada entre a dependência institucional e o valor da participaçáo autônoma.

\section{Refletindo e construindo caminhos}

A partir dessas consideraçóes, definiu-se que os processos socioculturais que envolvem a produção e a reprodução de significados comporiam o problema central para o qual seriam projetadas as novas açóes do Projeto Metuia com os jovens. Supôs-se, então, que seria oportuno fomentar atividades que envolvessem os diferentes atores sociais que compóem o território sociorrelacional no qual se dão esses processos, oferecendo oportunidades de reelaboração crítica sobre o jovem, seus interesses e suas ações. Desestabilizar concepçóes cristalizadas - e, muitas vezes, fortemente atravessadas por emoçóes que induzem ao medo, ao distanciamento ou até à ruptura de vínculos - poderia ser um primeiro passo para a formação de novos sistemas interpretativos nos quais as práticas sociais estão ancoradas, tendo em vista que, conforme afirma Moscovici (2003), as representaçóes sociais que nestes sistemas têm lugar são, em grande parte, responsáveis por guiar as açôes humanas. Suas consideraçôes enfatizam o caráter prescritivo das representaçóes sociais, uma vez que, para ele, estas são compostas por um conjunto de conceitos, afirmaçóes e explicações que são verdadeiras "teorias" do senso comum, "ciências coletivas" que servem não somente à interpretação da realidade, mas também à construção da realidade, e criam o ambiente no qual se desenvolve a vida. Um objeto de representação social é, então, um objeto de relevância ou "força" social para um grupo de sujeitos.

Compartilhando essa perspectiva, também Jodelet (2001) discutiu a função das representações sociais, afirmando, ainda, que estas são fenômenos complexos, sempre ativos na vida social. Segundo a autora, existe consenso na comunidade científica de que as representaçôes são

[...] uma forma de conhecimento socialmente elaborada e partilhada, com um objetivo prático, que concorre para a construção de uma realidade comum a um conjunto social (JODELET, 2001, p. 36).

Spink (1995), por sua vez, acentuou que as representaçôes são valorativas, mais do que conceituais, e respondem a ordens morais locais, ficando prenhes de afeto. Como conhecimentos práticos, estáo orientadas para o mundo social, fazendo e dando sentido às práticas sociais (SPINK, 1995).

Assim, apostar na possibilidade de que um projeto, com foco nas representações sobre os jovens poderia contribuir para a reconstrução dos olhares presentes no território abrangido pelas nossas experiências, impulsionou o processo de sua elaboraçáo. Foram, entâo, planejadas açóes que tivessem como ponto de partida a possibilidade de instituir um verdadeiro encontro intersubjetivo, ou seja, um encontro em que o que ocorre não se limita a uma relação mediada pela rigidez das ideias pré-concebidas, prévias ao momento real do encontro. Um encontro no qual fosse possível realizar uma construçáo compartilhada, fundamentada na comunicação e nas linguagens, em que se misturassem, a um só tempo, o pensamento primitivo, o senso comum e a ciência (MOSCOVICI, 2001). A ideia encontrou apoio, 
também, nas proposiçóes de Bosi (2003), para quem é preciso reencontrar os fenômenos face a face para recusar o estabelecido e o estereótipo, já que estes, configurando-se pela colheita de aspectos do real já recortados pela cultura, operam um empobrecimento das percepçóes por meio de mediaçôes impostas. Trata-se, para a autora, de questionar-se: "Como podemos encontrar o caminho das coisas se já nos disseram tudo antes que as experimentássemos?”.

Com base nessas noçóes, o projeto elaborado considerou o propósito de cooperar com processos culturais que concorrem para a ampliaçâoo da capacidade da comunidade, da rede educativa e assistencial, em acolher, compreender e gerar respostas mais efetivas aos problemas experimentados pelos jovens daquele território, tomando-os como sujeitos potentes e portadores de direitos. $\mathrm{Na}$ qualidade de projeto de extensão, $O$ território e seus protagonistas: novos olhares para a infância ${ }^{3}$ e juventude foi apresentado às instâncias universitárias e, após sua homologação, tem recebido recursos da Pró-Reitoria de Cultura e Extensão Universitária da Universidade de São Paulo, por meio dos quais se possibilita a participaçáo de quatro estudantes de terapia ocupacional em suas açóes e vem se desenvolvendo desde agosto de 2014.

\section{$3 \mathrm{O}$ projeto em andamento: configurações práticas e ações em curso}

Como se afirmou, o objetivo principal do projeto tem sido criar situaçóes em que seja possível a construçáo coletiva de novos pontos de vista acerca da infância e da juventude contemporânea, no âmbito do bairro do Butantã - e, em especial, acerca de crianças e jovens considerados em situação de vulnerabilidade ou de risco social, tendo em vista ser este o segmento abordado pelas políticas sociais.

As novas representaçóes que se quer fomentar se orientam, em primeira instância, pelo reconhecimento dos direitos de crianças e jovens. Contudo, enfatiza-se o fato de que, além de sujeito de direitos, os jovens são sujeitos potentes para a ação autônoma. Dar visibilidade a essa potência nos pareceu não somente essencial para alterar os pontos de vista atravessados pela desqualificação, como também uma ação muito pertinente à esfera da Terapia Ocupacional Social. Afinal, operar com os desejos, anseios e açôes desses jovens, bem como com as distintas formas de se comunicarem entre si e com o mundo, deve integrar as açóes de terapeutas ocupacionais, conforme referiu Lopes (2006, p. 12):
[...] Disponibilizar-se para conhecer as atividades de interesse dessa população, aprender novos recursos, compreender a atividade como elemento-meio, faz-se necessário e rico para novas vivências, para a mudança de formas de comunicação e para a criação de novas maneiras de ser, estar e conviver que contribuam para um fortalecimento pessoal e social das crianças, dos adolescentes e jovens de grupos populares.

Foi dessa perspectiva que trazer à vista e realçar as experiências juvenis que se desenvolvem alicerçadas, essencialmente, no seu protagonismo nos pareceu ser uma estratégia agregadora do conjunto de expectativas envolvidas no projeto.

Desse modo, o projeto vem buscando a participaçáo de diferentes grupos que integram o território sociorrelacional no qual se situa: a) famílias usuárias da rede socioassistencial do Sistema Único de Assistência Social no Butantã; b) profissionais que atuam na rede assistencial (como assistentes sociais, terapeutas ocupacionais, psicólogos, advogados, pedagogos, educadores sociais e oficineiros); e c) profissionais que, com a rede, se relacionam no âmbito de ações intersetoriais (como professores e profissionais da saúde). Cabe dizer que, considerando-se unicamente o âmbito da assistência social, a rede é composta pelo CRAS Butantã (unidade pública) e 39 unidades sem fins lucrativos, conveniadas e supervisionadas por esse centro de referência e distribuídas nos distritos: Vila Sônia, Butantã, Morumbi, Rio Pequeno e Raposo Tavares. Tais unidades ofertam diferentes serviços a crianças, jovens, adultos e idosos, e devem atender aos princípios e diretrizes da Política Nacional de Assistência Social. Como não poderia deixar de ser, o projeto tem dado prioridade à participação dos profissionais que atuam em unidades que oferecem serviços a crianças e jovens. Contudo, tem igualmente recebido profissionais que atuam junto a outros grupos populacionais. A estratégia adotada tem sido a promoçáo do contato e o diálogo entre a comunidade, os profissionais que atuam com a juventude e os jovens protagonistas de açôes no território, tomando, como eixo estruturador, a apreciação das seguintes realizaçôes - com prioridade para as primeiras:

a) produçóes culturais (teatro, dança, circo, música, artes visuais, literatura e artesanato) geradas por meio do protagonismo de crianças e/ou jovens em situação de risco ou vulnerabilidade social do bairro do Butantã ou de outras regiōes com altos índices de vulnerabilidade social do município de São Paulo; 
b) experiências exitosas da rede socioassistencial do município na promoção dos direitos de crianças e jovens;

c) experiências inovadoras e criativas, realizadas no âmbito das políticas para a infância e juventude, que estimulem a reflexão acerca das potencialidades locais para gerar iniciativas que respondam às demandas sociais.

Cabe, aqui, dar destaque a dois aspectos. O primeiro é que se considera indesejável que o contato entre os participantes se limite à apreciaçáo conjunta das produções, sendo uma exigência o seu par: uma interação em forma de diálogo que conecte os diferentes segmentos que se reúnem em torno da apresentação das produçôes ou experiências. Isto significa que cada reunião tem requerido uma organização própria, que garante a existência de espaço, tempo e recursos necessários para que isso aconteça. Além disso, o ambiente relacional deve prover estímulos para que sejam compartilhados os significados atribuídos pelos protagonistas à vivência individual e/ou coletiva do processo de produção.

Foram previstos dez encontros com as seguintes possibilidades de formato:

a) rodas de conversa;

b) eventos culturais que articulem a exposição de produçôes culturais individuais ou coletivas, e o diálogo com os autores (acerca de sua história, do processo de trabalho realizado e/ou de temas conectados à produção exposta);

c) oficinas de criação (cultural ou artística) que permitam a expressão e a reflexão compartilhada acerca de temas pertinentes.

O segundo aspecto a ser destacado é a prioridade do projeto para a exposiçáo da produção cultural de jovens ou grupos de jovens do Butantã que tenham uma história de constituição e evolução independente de adultos ou organizaçóes assistenciais. Não estáo excluídos os grupos que se originaram e se desenvolveram sob orientação ou com apoio destes, mas busca-se valorizar as experiências nas quais seja inequívoca a motivação dos jovens para dar início e prosseguimento às suas produções.

A modalidade de cada uma das reunióes, bem como seu local, vem sendo eleita de acordo com o que se considera mais adequado face à natureza das produções ou experiências que serão apresentadas, ao favorecimento do acesso dos participantes e também à natureza participativa e aberta dos encontros.

\section{Alguns pontos avistados}

Considerando-se que o projeto ainda está em desenvolvimento, seria precoce produzir sobre ele qualquer discussão a título de conclusão. Mas é possível apresentar algumas consideraçôes, que se fizeram a partir do levantamento dos coletivos juvenis do território (primeira fase de execução do projeto) e da realização de alguns encontros.

$\mathrm{O}$ projeto teve início com a identificação e a localização de produções culturais claramente marcadas pelo protagonismo juvenil no âmbito do território abrangido, bem como de práticas sociais que promovem a defesa de direitos desses segmentos. Para tanto, se optou por um processo de levantamento dessas experiências junto à rede mundial de computadores (incluindo as redes sociais), a escolas, fóruns de discussão, equipamentos culturais e coletivos, associaçôes ou Organizaçóes não governamentais que atuam no campo das artes e da cultura.

A partir da consolidação de um cenário preliminar, iniciaram-se açôes de aproximação com essas experiências, visando a conhecer autores, processos de trabalho e produçôes, bem como o interesse desses jovens em tomar parte das atividades do projeto. Nessa aproximação dialogada, foi importante confirmar o protagonismo dos jovens, tanto quanto explicitar os sentidos do projeto proposto. Foi importante, também, alcançar informaçóes sobre outras experiências conhecidas por esses jovens, mediante participação em circuitos pouco institucionalizados ou divulgados, a fim de complementar o cenário preliminar.

Nessa etapa inicial, um primeiro fato importante foi identificado: não havia no território, como se pensava, um conjunto extenso de experiências juvenis com as características delimitadas pelo projeto, mas, ao contrário, um pequeno número destas. Para melhor caracterizar o impacto dessa observaçáo, convém revelar que, apesar de não pretender se fixar em faixa etária específica, o projeto se desenvolvia sob uma expectativa implícita de identificação e contato com experiências cujos protagonistas fossem jovens adolescentes, ou seja, jovens que têm entre 15 e 17 anos (CASTRO et al., 2009). Tendo partido de reflexóes e experiências prévias junto a essa faixa etária, o projeto se conectava a um contexto de reflexôes e práticas sociais que a abrangiam. Porém, a realidade identificada pelo levantamento, ainda que mostrasse experiências muito importantes do ponto de vista qualitativo, apontou para um conjunto relativamente pequeno de experiências protagonizadas por jovens adolescentes. 
A pequena dimensão numérica do conjunto dessas experiências, embora sendo uma constatação sem rigor acadêmico, pode ser admitida ao se realizar a comparação com outras regiôes da cidade de São Paulo. Conforme discutem Almeida (2013) e Caldeira (2014), desde a virada do milênio, diversas expressôes culturais tornaram-se componentes importantes dos cenários das periferias, frequentemente associadas a propostas de apropriação e "ressignificação" de espaços públicos ou privados. Já na década de 2010, tem sido, sobretudo, por meio da produção cultural - e não dos movimentos sociais - que os espaços públicos vêm sendo transformados, tão grande é a força de mobilização dessas expressôes (CALDEIRA, 2014). Dessa perspectiva, o território no qual se realiza o projeto não se revelou um espaço fortemente marcado pela conexáo dos jovens adolescentes com tais experiências culturais. Dados do Programa VAI - Valorização de Iniciativas Culturais, promovido pela Secretaria Municipal de Cultura do município de São Paulo - também sugerem que a presença dos empreendimentos culturais dos jovens do Butantã é discreta. Na lista de projetos contemplados pelo programa em 2015, do total de 231 projetos, apenas oito são provenientes da Zona Oeste da cidade, na qual se situa o bairro do Butantá. É importante mencionar que esse programa vem sendo avaliado positivamente, no que diz respeito ao seu objetivo de fomentar açóes culturais produzidas por jovens e no que tange ao fortalecimento da ideia do direito à cultura na cidade (ALMEIDA, 2013). O programa tem destinado em torno de 20 mil reais para cada projeto que, anualmente, é apresentado por coletivos ligados à cultura. Embora se trate de um valor modesto, da perspectiva de Almeida (2013), trata-se de uma ação inovadora e ousada, já que, com todas as concepçóes que ainda associam o jovem à irresponsabilidade, o programa se propóe a transferir recursos diretamente para jovens pobres, moradores de regiôes periféricas, invertendo a ordem do discurso burocrático e apostando no compromisso desses coletivos que, em sua maioria, se organizam de forma espontânea e informal.

Finalmente, se por um lado, a presença pouco expressiva numericamente de coletivos juvenis ligados à cultura tem gerado dificuldades para a concretização do projeto, leva, por outro lado, à expansão de indagaçôes que se inserem coerentemente no plano das intervençóes pretendidas. Afinal, o que as organizaçóes e a rede de apoio social que atuam com esses jovens têm a ver com isso? Não estariam deixando de oferecer condiçôes para que esses jovens realizem atividades com mais autonomia, conjugando o direito à expressão, à liberdade e ao compromisso no âmbito das expressóes culturais?

Outro ponto evidenciado no processo realizado até os dias atuais é a dificuldade de atrair os profissionais que atuam na rede para conhecerem e dialogarem sobre as experiências de protagonismo juvenil. Esse é um fato que precisa ser mais bem compreendido, tanto porque disso depende o bom andamento do projeto, quanto porque náo se quer reproduzir uma visão estreita e precipitada de que o "problema" reside no outro, o que, neste caso, significaria atribuir aos profissionais um suposto desinteresse. Assim, algumas alteraçóes no projeto têm sido realizadas, ao mesmo tempo em que se busca um melhor nível de compreensão. Atualmente, os encontros têm sido realizados nos próprios ambientes de trabalho dos profissionais, a fim de evitar a necessidade de seu deslocamento. A partir da consulta a uma unidade assistencial acerca de seu interesse em receber as atividades do projeto, o planejamento do encontro incorpora as melhores condiçóes apresentadas por esta para a participação dos seus profissionais, ainda que o convite náo seja restrito a estes. Inicialmente, é possível dizer que a nova fórmula trouxe algumas melhorias, mas também novos desafios. Se, por um lado, ampliou a participação dos profissionais da rede, por outro lado, impôs a aceitaçáo de um ritmo que é dependente das inúmeras atividades que, regulares ou não, preenchem a agenda dos serviços e de seus profissionais.

Por fim, cabe destacar que tem sido possível registrar processos importantes que não haviam sido previstos. Estes dizem respeito, essencialmente, à abertura de possibilidades de comunicação e intercâmbio entre os jovens de diferentes coletivos, que também se distinguem quanto às oportunidades que vivenciam para protagonizar açôes com valor social. Concomitantemente, processos de identificação e de valorizaçăo mútua, de respeito e de apreço à pluralidade cultural, bem como açóes impulsionadas pela solidariedade, têm despontado num cenário árido como que para refutar a tese do individualismo exacerbado da juventude. Sáo resultados inesperados que podem contribuir, decisivamente, para a inclusáo de referências positivas na esfera das representaçôes sociais sobre a juventude.

\section{Referências}

ABRAMO, H. Consideraçóes sobre a tematização social da juventude no Brasil. In: FÁVERO, O. et al. Juventude e contemporaneidade. Brasília: UNESCO, 2007. p. 73-90.

ALMEIDA, R. S. Juventude, direito à cidade e cidadania cultural na periferia de São Paulo. Revista do Instituto de Estudos Brasileiros, São Paulo, n. 56, p. 151-172, 2013. 
BARROS, D. D.; ALMEIDA, M. C.; VECCHIA, T. C. Terapia ocupacional social: diversidade, cultura e saber técnico. Revista de Terapia Ocupacional da Universidade de São Paulo, São Paulo, v. 18, n. 3, p. 128-134, 2007.

BOSI, E. O tempo vivo da memória: ensaios de Psicologia Social. São Paulo: Ateliê Editorial, 2003.

BRASIL. Estatuto da Criança e do Adolescente. Lei Federal no 8069, de 13 de julho de 1990. Dispóe sobre o Estatuto da Criança e do Adolescente e dá outras providências. Diário Oficial [da] República Federativa do Brasil, Brasília, DF, 16 jul. 1990. Disponível em: <http:// www.planalto.gov.br/ccivil_03/Leis/l8069.htm>. Acesso em: 13 maio 2015.

BRASIL. Ministério do Desenvolvimento Social e Combate à Fome. Traçado metodológico Projovem Adolescente: serviço socioeducativo. Brasília, 2009.

BRASIL. Secretaria Nacional de Juventude. Estação juventude: conceitos fundamentais - ponto de partida para uma reflexão sobre políticas públicas de juventude. Brasília, 2014

CALDEIRA, T. P. R. Gênero continua a ser o campo de batalhas: juventude, produção cultural e a reinvenção do espaço público em São Paulo. Revista USP, São Paulo, n. 102, p. 83-100, 2014.
CASTRO, J. A.; AQUINO, L. M. C.; ANDRADE, C. C. Juventude e politicas sociais no Brasil. Brasília: IPEA, 2009.

ESTEVES, L. C. G.; ABRAMOVAY, M. Juventude, Juventudes: pelos outros e por elas mesmas. In: ABRAMOVAY, M.; ANDRADE, E. R.; ESTEVES, L. C. G. Juventudes: outros olhares sobre a diversidade. Brasília: Ministério da Educação, 2007. p. 19-54.

GEERTZ, C. A interpretação das culturas. Rio de Janeiro: LTC, 2008.

JODELET, D. As representaçóes sociais. Rio de Janeiro: EdUERJ, 2001.

LOPES, R. E. Terapia Ocupacional Social e a infância e a juventude pobres: experiências do núcleo UFSCAR do Projeto Metuia. Cadernos de Terapia Ocupacional da UFSCar, São Carlos, v. 14, n. 1, p. 5-14, 2006.

MOSCOVICI, S. Das representaçóes coletivas às representaçōes sociais: elementos para uma história. In: JODELET, D. As representaçóes sociais. Rio de Janeiro: EdUERJ, 2001. p. 45-66.

MOSCOVICI, S. Representaçôes sociais: investigações em psicologia social. Rio de Janeiro: Vozes, 2003.

SPINK, M. J. O conhecimento no cotidiano: as representações sociais na perspectiva da psicologia social. Sáo Paulo: Brasiliense, 1995.

\section{Contribuição dos Autores}

As autoras Marta Carvalho de Almeida e Carla Regina Silva Soares são responsáveis pela concepção e coordenação da experiência relatada e redigiram o texto. As autoras Ana Terra dos Santos Barbosa, Danielle Peralta Kazanji, Mariana Silva Lima e Pérola Prado participam das atividades relatadas e complementaram o texto, cada qual, com contribuiçóes específicas. Todos os autores aprovaram a versão final do texto.

\section{Fonte de Financiamento}

Pró-Reitoria de Cultura e Extensão Universitária da Universidade de São Paulo.

\section{Notas}

${ }^{1} \mathrm{O}$ texto consiste em relato de experiência do projeto de extensão "O território e seus protagonistas: novos olhares para a infância e juventude”, coordenado por Marta Carvalho de Almeida e financiado pela Pró-Reitoria de Cultura e Extensão da Universidade de São Paulo.

${ }^{2}$ Considerando-se a polissemia do termo "cultura”, cabe salientar que aqui são adotadas as consideraçōes de Geertz (2008). O autor propóe que a cultura se refere a "[...] um sistema de concepçôes herdadas expressas em formas simbólicas, por meio das quais os homens comunicam, perpetuam e desenvolvem seu conhecimento e suas atividades em relaçáo à vida." (GEERTZ, 2008, p. 66).

${ }^{3}$ A proposta de incluir a infância no escopo das açôes do projeto teve por base a ideia de não sugerir que este estava ligado, com exclusividade, a uma faixa etária delimitada, o que poderia acontecer dadas algumas definiçóes correntes sobre juventude. Deixar o processo aberto a representaçóes implicadas nas práticas sociais que envolvem o segmento que ainda não alcançou a fase adulta foi considerado mais relevante. 